\title{
Performance and behaviour of rabbit does in a group-housing system with natural mating or artificial insemination
}

\author{
Jorine M. ROMMERS ${ }^{\mathrm{a} *}$, Cristiano BOITI ${ }^{\mathrm{b}}$, Ingrid DE JONG ${ }^{\mathrm{a}}$, \\ Gabrielle BRECCHIA ${ }^{\mathrm{b}}$ \\ ${ }^{a}$ Animal Sciences Group of Wageningen University and Research Centre (ASG) PO Box 65, 8200 AB \\ Lelystad, The Netherlands \\ ${ }^{\mathrm{b}}$ Dipartimento di scienze biopatologiche ed igiene delle produzioni animali e alimentari, Sezione di \\ Fisiologia veterinaria, Laboratorio di biotecnologie, Università degli studi di Perugia, \\ via S. Costanzo 4, 06100 Perugia, Italy
}

(Received 2 March 2006; accepted 7 July 2006)

\begin{abstract}
This study compared reproductive performance and behaviour of does raised in a grouphousing system and in a regular cage system. The group-housing pen was divided into different functional areas for suckling, resting, and eating and special hiding areas for kits when they had left the nest-boxes and does to favour the species specific behavioural traits. Does had access to their nest-box by means of an individual Electronic Nest-box Recognition System (ENRS) activated by a coded transponder placed in their eartags. Eight does were housed in each pen. Natural mating (NM, with a buck in the group) or artificial inseminations (AI) were applied. Litter size, kit mortality and kit weight at $14 \mathrm{~d}$ of age were similar for group-housing and cages when NM were applied. With a natural reproduction rhythm group-housing led to an increase of $+38 \%$ of litters. However, from a management point of view, a cycled production system with AI is preferred. With AI and grouphousing, a lower kindling rate and a lower kit weight at weaning were found. The lower kindling rate was partly caused by pseudo-pregnancies that were found in $23 \%(P<0.01)$ of the does in the group-housing system against $0 \%$ in the control group. Sixteen to $20 \%$ of the does in the grouphousing system had skin injuries, which is an indicator for aggression among does. Most of the injuries were seen on the body and most of them were superficial bites. Based on the results of this study, it can be concluded that group-housing of rabbit does seems possible, but more research is needed to solve the problems of the decreased kindling rate and occurrence of pseudo-pregnancies, the lower weight at weaning and aggressiveness among does.
\end{abstract}

rabbits / reproduction / group-housing / behaviour / welfare / pseudo-pregnancy

\section{INTRODUCTION}

In commercial rabbit production, rabbit does are commonly housed individually in

\footnotetext{
* Corresponding author:

Jorine.Rommers@wur.nl
}

standard wire cages $(60-65 \times 40-50 \mathrm{~cm})$ and raised under a semi-intensive breeding rhythm (inseminations 11 days post partum, PP). However, in laboratory conditions, the does frequently show disturbed behaviours such as repetitive hair-chewing, 
Table I. Distribution of the treatments in the experiments.

\begin{tabular}{lll}
\hline Treatment & Housing & Breeding \\
\hline Experiment 1 & Pens: $n=24$ & Natural mating: early PP \\
Farm $1+2$ & Cages: $n=24$ & Natural mating: early PP \\
& Cages: $n=24$ & Natural mating: $10-12 \mathrm{~d} \mathrm{PP}$ \\
Experiment 2 & Pens: $n=24$ & Artificial insemination: $10-12 \mathrm{~d}$ PP \\
Farm 1 & Cages: $n=16$ & Artificial insemination: $11 \mathrm{~d}$ PP \\
& Pens: $n=24$ & Artificial insemination: $11 \mathrm{~d} \mathrm{PP}$ \\
Farm 2 & Cages: $n=24$ & Artificial insemination: $11 \mathrm{~d} \mathrm{PP}$ \\
& &
\end{tabular}

${ }^{1} \mathrm{PP}$ : post partum.

bar-chewing, and head sawing, suggesting that basic ethological requirements are not satisfied and welfare is impaired [1,2].

Therefore, over the past few years new cage designs have been developed to better satisfy the welfare needs of the does so that they can stand up, and use an elevated platform to stimulate locomotion and withdraw from the kits when they leave the nest-box [3-5]. However, albeit these "welfare" oriented cages greatly improve species specific ethological requirements, they do not allow social interaction between does given that they are raised in individual cages.

On the contrary, group-housing would meet the natural need of rabbits for social interaction with mates [5,6]. However, several problems such as poor sanitary conditions, aggression, and a high kit mortality due to nest box competition among does, have not allowed good performances until now (personal communication). Therefore, in order to circumvent these drawbacks, a new group-housing system was developed at our Institute [7] based on the principles proposed by Stauffacher [5]. Accordingly, the pen was divided into functional units for breeding, feeding, and an area where does can hide from kits after leaving the nest-boxes [5]. In our system, the relatively high loss of kits in the nest-box was prevented by using an individual electronic nest-box recognition system (ENRS) that allows each doe a unique access to her own nest-box [7]. Although reproductive performance in this group- housing system was comparable to the standard wire cage system [8], these results were obtained under conditioned circumstances not reflecting those real field operational conditions. In addition, the reasons for the poor reproductive performance of does raised in group pens when inseminated artificially at fixed time post partum are still unclear.

Therefore, a study was carried out to compare performance and behaviour of rabbit does submitted to a group-housing system provided with ENRS or an individual cage system, when natural mating (NM) or artificial insemination (AI) is applied under field conditions.

\section{MATERIALS AND METHODS}

Two experiments were run at two commercial rabbit farms each in The Netherlands. In the first experiment NM was applied, whereas AI in the second. Both experiments lasted approximately 6 months (April to December 2004, March to August 2005) as summarised in Table I. The use and care committee of the animal sciences group of Wageningen university and research centre approved all protocols. 


\subsection{Treatments}

\subsubsection{Housing: group-housing vs. individual cages}

On each farm, three pens for the grouphousing system provided with ENRS were installed in one compartment of the farm together with 24 or 48 (see Tab. I) individual standard wire cages $(50 \times 60 \times 30: \mathrm{w} \times$ $1 \times \mathrm{h}$ ) that were used as the control group. The pens (Fig. 1) had a dimension of $2.3 \times$ $1.7 \mathrm{~m}(1 \times \mathrm{w})$ and were open at the top. The floor consisted of wire or artificial plastic slats. The nest-boxes were elevated so that the kits fell on the floor when they get out of the nest-box for the first time. In this way it was prevented that kits, old enough to leave the nest-box, could move back into other nest-boxes. There was a separate area on the floor for the kits where does had no entrance. Underneath the nest-boxes, a resting area for the does was created, because does prefer to lie underneath a cover [9]. Eight does were housed in each pen.

\subsubsection{Breeding rhythm: natural mating or artificial insemination}

In the first experiment a buck was introduced into the group allowing an eventual post-partum mating. For the does in the cages, NM was applied post partum or 10-12 days after kindling. In the second experiment, there was no buck in the group and all the does were inseminated artificially 11 days post partum allowing a cycled production system. Table I gives an overview of treatments and number of animals involved.

The first experiment lasted for approximately 6 months, when does had produced approximately 3 litters. In the second experiment does were inseminated for three successive reproductive cycles.

\subsection{Animals and husbandry}

The experiments started with nulliparous New Zealand White hybrid does that were bred at the farms. At each farm, 24 does were housed in three pens and 48 (Exp. 1) or 16 or 24 (depending on the farm, Exp. 2) does were housed individually in cages. Does that were culled during the experiment were replaced by nulliparous does.

In the first experiment, the does aged 17 weeks were placed in the pen, followed by the buck a few days later.

In the second experiment, does at around 17 weeks of age were inseminated for the first time in the cages and 24 pregnant does were transferred to the pens two weeks before first parturition. After first kindling, these does were inseminated 11 days post partum. Receptivity of all does was evoked by closing the nest boxes $24 \mathrm{~h}$ prior to AI. The artificial inseminations were performed with fresh mixed sperm obtained from a commercial AI-station in the Netherlands. A GnRH analogue $(0.2 \mathrm{~mL}$ containing $0.00084 \mathrm{~mL}$ Buseriline-acetate; Receptal, Intervet, Boxmeer, The Netherlands) was administered i.m. immediately after insemination to induce ovulation.

Does had access to their own nest-box by the ENRS from the day they were placed into the pens onwards. After kindling, the litters were standardised to eight (first parity) or 9-10 kits (second parity). Cross-fostering was applied within treatments. Nest-boxes were closed three weeks after parturition and kits were placed on the floor of the pen. In the first experiment, kits in the group-housing were weaned around $600 \mathrm{~g}$, whereas those in the cages at 30 days of age. In the second experiment, kits were weaned at 32 or 35 days, depending on the standard weaning procedure at the farm.

Does and kits were fed ad libitum a standard commercial lactating diet that was 

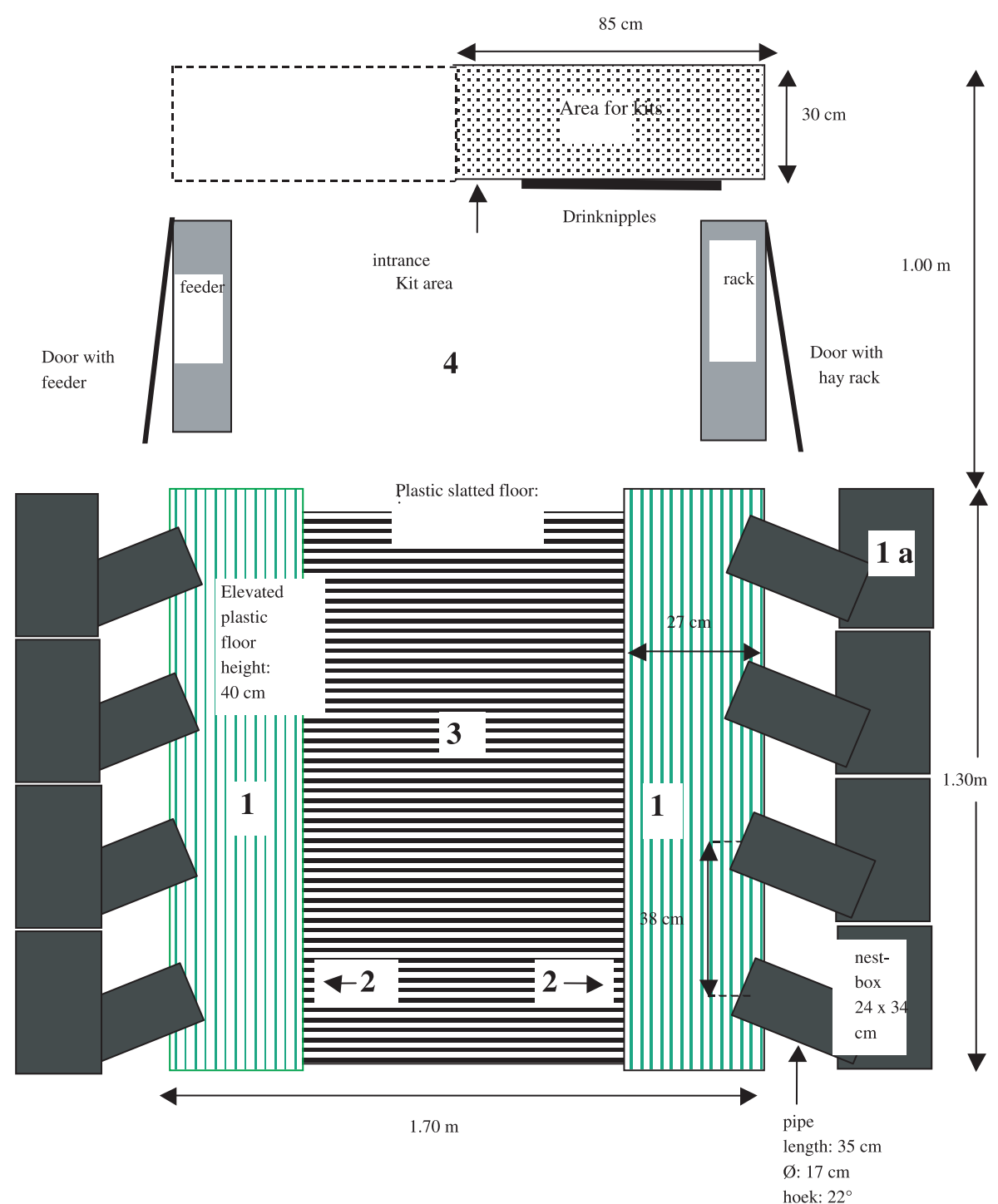

Figure 1. Design of the group-housing pens;

1 = Elevated floors to enter nestboxes;

$1 \mathrm{a}=$ Nestboxes;

$2=$ Resting area underneath the elevated floors;

$3=$ Floor of the pen, constructed from galvanised wire or alternative slats;

$4=$ Feeding area. 
used at the farm and straw was provided ad libitum in a rack. Water was provided ad libitum through drinking nipples. The animals were kept in a $16 \mathrm{~h}$ light, $8 \mathrm{~h}$ dark lighting scheme.

\subsection{Measurements}

\subsubsection{Reproduction, kit viability and growth}

The following parameters were recorded: number of alive and still born kits, number and weight of the litter at $14 \mathrm{~d}$ of age (all experiments), and number and weight of the litter at weaning (second experiment). Litter weight at $14 \mathrm{~d}$ was taken as a measure for milk production, because at this age all kits were still in the nest-box. As soon as kits were on the floor, it was not possible to trace them back to the doe they belonged to.

Blood samples. In the second experiment, blood samples were taken by ear veni puncture one day before insemination from all the does in group-housing and from 20 does in the cages at two farms (10 does/farm) in the second reproductive cycle. The second cycle was chosen because this was the first cycle in which pseudo-pregnancies could be detected. At the moment of insemination of the first cycle, does were still housed in cages $(17 \mathrm{w}$ of age). One milliliter of blood was collected into tubes containing EDTA. Blood samples were centrifuged for $10 \mathrm{~min}$ at $3000 \mathrm{~g}$ and plasma was transferred into cups and stored at $-20{ }^{\circ} \mathrm{C}$ until being assayed for progesterone concentrations to assess the functional status of the ovarian CL. For the purpose of this work, according to Boiti et al. [10], blood levels below $2.0 \mathrm{ng} \cdot \mathrm{mL}^{-1}$ were considered as basal and indicative of non pseudo-pregnant does $(\mathrm{P}-)$, while levels greater than $2.0 \mathrm{ng} \cdot \mathrm{mL}^{-1}$ were indicative of pseudo-pregnant doe $(\mathrm{P}+)$.

\subsubsection{Progesterone assay}

Plasma progesterone concentrations were determined in duplicate by RIA, using specific antibodies according to the procedure reported elsewhere [10]. Progesterone was extracted from $0.1 \mathrm{~mL}$ of plasma with ethyl ether. The assay sensitivity was $0.08 \mathrm{ng} . \mathrm{mL}^{-1}$ and intraand inter-assay coefficients of variations were $5.3 \%$ and $10.2 \%$, respectively.

\subsection{Observations}

\subsubsection{Skin injuries}

Skin injuries were scored as an indicator of aggression among does in groups. The does were examined once every month for skin injuries by the same observer. Different parts of the body (body and limbs, head and ears, genitals) were scored for skin injuries according to Kalle [11] using the following scale: $0=$ no injuries; $1=$ superficial bites $(<1 \mathrm{~cm})$, that normally heal within a couple of days; $2=$ moderate to severe injuries $(>1 \mathrm{~cm})$, and $3=$ open wounds.

\subsubsection{Mounting behaviour}

In the second reproduction cycle, the pens were monitored by video recording for $23 \mathrm{~h} / \mathrm{d}$ from kindling to the day of insemination. Does were marked differently with the violet spray, so that they could be recognised individually. From the reply of tapes we traced back which does were mounted by other does.

\subsection{Statistical analysis}

\subsubsection{Reproduction, kit viability and growth}

Analyses of variance were carried out using the GLM procedure of SAS (SAS, 
Table II. Productivity of the does, kit growth and viability in group housing or individual housing with natural mating. LSmean and s.e. are presented.

\begin{tabular}{lcccccc}
\hline Treatment & Group & Cage & Cage & $\begin{array}{c}\text { Effect } \\
\text { treatment } \\
P \text { value }\end{array}$ & $\begin{array}{c}\text { Effect } \\
\text { farm } \\
P \text { value }\end{array}$ & $\begin{array}{c}\text { Effect } \\
\text { treatm. } \times \text { farm } \\
P \text { value }\end{array}$ \\
Breeding rhythm & $\mathrm{NM}^{1}$ & $\mathrm{NM}$ & $10-12 \mathrm{~d} \mathrm{PP}^{2}$ & $P$ val \\
\hline Litters, No. & 173 & 125 & 137 & & & \\
Litter size, No. & $9.7 \pm 0.2$ & $9.3 \pm 0.2$ & $9.7 \pm 0.2$ & 0.51 & 0.77 & 0.62 \\
Kits born alive, No. & $9.1 \pm 0.3$ & $8.7 \pm 0.3$ & $9.0 \pm 0.3$ & 0.46 & 0.12 & 0.32 \\
Kit weight at 14 d, g & $233 \pm 4$ & $241 \pm 5$ & $241 \pm 5$ & 0.23 & 0.0001 & 0.08 \\
Kit mortality at 14 d, \% & $12.8^{\mathrm{a}}$ & $8.8^{\mathrm{ab}}$ & $5.2^{\mathrm{b}}$ & 0.02 & 0.04 & 0.85 \\
\hline
\end{tabular}

${ }^{1} \mathrm{NM}$ : natural mating; natural reproductive rhythm; ${ }^{2} \mathrm{PP}$ : post partum.

Inst. Inc., Cary, NC, USA). For experiment 1 , data were analysed with farm ( 2 levels) and treatment ( 3 levels) and their interaction as fixed effects, whereas in experiment 2 also reproduction cycle was also added to the model as the fixed effect. In experiment 2 , the number of kits and kit weight at weaning were analysed with the model with the pen as the experimental unit. Skewed distributions of portion (kit mortality at $14 \mathrm{~d}$ ) were arcsine square root transformed to obtain homogeneity of variances. Differences between LSmeans were analysed by the PDIFF option of the GLM procedure of SAS. Data are presented as LSmeans and standard errors. Differences in kindling rate between treatments were analysed with a Chi-squared test.

\subsubsection{Progesterone concentration}

Differences among the percentages of $\mathrm{P}+$ and $\mathrm{P}-$ does between treatments were analysed by a Chi-squared test.

\subsubsection{Skin injuries}

The percentage of does that had moderate to severe skin injuries and open wounds was calculated. Average distribution of injuries over the different body parts was calculated.

\section{RESULTS}

\subsection{Reproduction, kit viability and growth}

Reproductive performance of the first experiment (NM) is presented in Table II. Kindling rate could not be calculated, because the number of natural mating was unknown in group housing. Therefore, the total number of litters produced during the experimental period was calculated. Compared with an early or 10-12 d post partum rhythm in cages, a natural reproduction rhythm in group housing led to an increase of respectively $+38 \%$ and $+26 \%$ of litters.

The number of alive and still born kits as well as kit weight at $14 \mathrm{~d}$ did not differ between group- and individual housing. Kit mortality at $14 \mathrm{~d}$ was higher in grouphousing compared to semi-intensive breeding in cages (12.8 vs. 5.2, respectively; $P<0.05)$. For kit mortality at $14 \mathrm{~d}$ and kit weight at $14 \mathrm{~d}$, there were differences between farms $(P<0.05$ and $P<0.001$, respectively).

Reproductive performance in the second experiment (AI) is presented in Table III. Most of the parameters differed between farms $(P<0.05)$. The interaction term farm $\times$ treatment $\times$ cycle was significant $(P<0.05)$ for total litter size and kit mortality at $14 \mathrm{~d}$. Overall, kindling 
Table III. Productivity of does, kit growth and viability in group housing or individual housing with artificial insemination. LSmean and s.e. are presented.

\begin{tabular}{|c|c|c|c|c|c|}
\hline Breeding rhythm & $11 \mathrm{dPP}^{1}$ & $11 \mathrm{~d}$ PP & $\begin{array}{l}\text { Effect } \\
\text { treatment } \\
P \text { value }\end{array}$ & $\begin{array}{l}\text { Effect } \\
\text { farm } \\
P \text { value }\end{array}$ & $\begin{array}{c}\text { Effect } \\
\text { treatment } \times \text { farm } \\
P \text { value }\end{array}$ \\
\hline Litters, No. & 102 & 101 & & & \\
\hline Kindling rate, $\%$ & 55.6 & 84.2 & 0.001 & & \\
\hline Total litter size, No. & $8.4 \pm 0.3$ & $8.9 \pm 0.3$ & 0.19 & 0.001 & 0.77 \\
\hline Kits born alive, No. & $7.7 \pm 0.3$ & $8.4 \pm 0.3$ & 0.16 & 0.002 & 0.94 \\
\hline Kit mortality at $14 \mathrm{~d}, \%$ & 10.1 & 7.4 & 0.15 & 0.002 & 0.11 \\
\hline Kit weight at $14 \mathrm{~d}, \mathrm{~g}$ & $233 \pm 12$ & $241 \pm 11$ & 0.60 & 0.02 & 0.07 \\
\hline No. kits at weaning & $6.6 \pm 0.5$ & $6.9 \pm 0.2$ & 0.58 & 0.18 & 0.83 \\
\hline Kit weight at weaning, $g$ & $720 \pm 25$ & $841 \pm 12$ & 0.001 & 0.001 & 0.18 \\
\hline
\end{tabular}

${ }^{1}$ PP: post partum.

rate was significantly lower for the grouphousing as compared to the cages (55.6 vs. $84.2 \%$, respectively; $P<0.001)$. Kit weight at $14 \mathrm{~d}$ of age was similar for the treatments, whereas at weaning kit weight was significantly lower for group housing compared to cages (720 vs. $841 \mathrm{~g}$, respectively).

\subsection{Progesterone levels and mounting behaviour}

The progesterone $(\mathrm{P} 4)$ concentrations one day before insemination in the second reproduction cycle are presented in $\mathrm{Ta}$ ble IV. In the group-housing group, $23.9 \%$ $(P<0.01)$ of the does $(11 / 47)$ were $\mathrm{P}+$ with plasma $\mathrm{P} 4$ concentration of $5.7 \pm$ 0.6 ng. $\mathrm{mL}^{-1}$ (mean \pm SEM), whereas in the individual-cage group all the does were $\mathrm{P}-\left(0.7 \pm 0.04\right.$ ng. $\left.\mathrm{mL}^{-1}\right)$. However, there were differences between pens (from none to $50 \%$ high $\mathrm{P} 4$ level). Kindling rate of $\mathrm{P}+$ does in group-housing was very low $(9.1 \%$; $1 / 11 ; P<0.01)$, whereas that of $\mathrm{P}-$ does $\left(0.9 \pm 0.7\right.$ ng.mL $\left.{ }^{-1}\right)$ was high $(88.6 \%)$ and not significantly different from the kindling rate of control does raised in individual cages $(95 \%)$.
Table IV. Distribution of does with high or low plasma progesterone concentrations at the day before artificial insemination in the second reproductive cycle of does housed in grouphousing or cages.

\begin{tabular}{|c|c|c|c|c|}
\hline Housing & \multicolumn{4}{|c|}{ Group-housing Individual-cage } \\
\hline Animals, No. & \multicolumn{2}{|c|}{47} & \multicolumn{2}{|c|}{21} \\
\hline P4 concentration & High $^{1}$ & Low $^{1}$ & High $^{1}$ & Low $^{1}$ \\
\hline Animals, $\%$ & 23.9 & 76.1 & 0 & 100 \\
\hline Kindling rate & 9.1 & 88.6 & - & 95.0 \\
\hline
\end{tabular}

Mounting behaviour was only seldom observed (3 times in two different pens). Does that were observed mounting did not have high $\mathrm{P} 4$ levels the day before insemination.

\subsection{Skin injuries}

Percentage of does with skin injuries and their body distribution are presented in Table V. Around $20 \%$ of the does had injuries in group-housing. Most of the injuries were observed on the body. In experiment $1,27.7 \%$ of the injuries were 
Table V. Percentage of does with moderate to severe skin injuries and part of the body that was injured for does housed in group-pens during two experiments.

\begin{tabular}{lcccc}
\hline & Animals injured \% & \multicolumn{3}{c}{ Part of the body that was injured (\% of total injuries) } \\
\cline { 3 - 5 } & & Head + ears & Body & Genitals \\
\hline Experiment 1 & 21.0 & 1.3 & 98.7 & - \\
Experiment 2 & 16.8 & - & 97.8 & 2.2 \\
\hline
\end{tabular}

Animals, \% $\rightarrow$ pen $1 \rightarrow$ pen $2-\Delta-$ pen 3

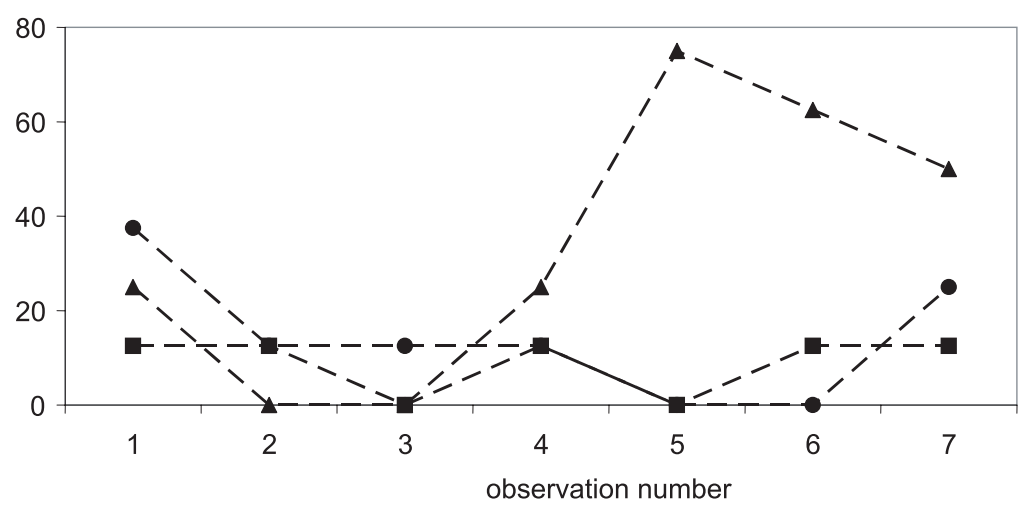

Figure 2. Percentage of does with skin injuries in 3 group-housing pens on one farm scored once every month.

moderate to severe, whereas in experiment 2 this percentage was $8.9 \%$.

Figure 2 shows the percentage of does with moderate to severe skin injuries in three pens at one farm in the first experiment (with a buck in the group). At the start there was an increased percentage of does with skin injuries. Then the level decreased below $10 \%$. In the 5th month of experimentation, a sudden rise in the percentage of does with injuries (to $77 \%$ of the does) was seen in one pen.

\section{DISCUSSION}

The present results show that group housing with a buck in the group leads to a $+38 \%$ increase of the number of litters produced with a natural reproduction rhythm compared to cage housing. This could partly be explained that with a buck in a group does can be mated continuously. In cages, it depends on the farmers' management when does will be brought to the buck, which might not always be as accurate.

The results confirm that, under field conditions, the number of kits born alive and stillborn and kit weight at $14 \mathrm{~d}$ of does in group-housing is similar to that of does raised in cages only when natural mating is applied. This was in agreement with previous findings of Coenen and Ruis [8], who reported similar performances under laboratory conditions. In group housing pens without the ENRS high kit mortality rates have been found (personal communication). Kit mortality at $14 \mathrm{~d}$ in grouphousing is similar to that in individual cages, when post-partum mating is applied. This might be due to the use of the ENRS that protect the young kits from being 
damaged by other does. Also kit weight at $14 \mathrm{~d}$ in the group-housing group was similar to that of individual cages whatever the reproduction rhythm, thus suggesting that milk intake up to $14 \mathrm{~d}$ of age was not affected by the raising system. Coenen et al. [13] reported that in group- housing provided with the ENRS, the does visit the next-boxes for longer than $60 \mathrm{~s}$ (that could be regarded as suckling) 2 to 3 times a day, a frequency that can be regarded as normal nursing behaviour. The ENRS worked well during the experiments, although in a few cases the does lost their ear tags incorporating the transponders.

With natural mating it is difficult to obtain an accurate weight of the kits at weaning, because, once on the floor, their age varies and kits can not be identified anymore. Conversely, with AI used in a cycled production system, kits have the same age. At weaning, kits weight was lower in group-housing compared to that in individual-housing. An explanation for this lower kit weight at weaning could be due to lower feed intake of the kits and/or a sudden interrupted suckling once on the floor. However, more research is necessary to precisely determine the causes for the lower kit weight at weaning.

From both management and hygienic points of view, AI in a cycled production system is preferred. Natural mating in the group housing system is not favoured because there is no good overview and control over the animals. Does kindle at different unpredictable days, resulting in a large variety of weaning ages. This hampers the delivery of a homogenous group of meat rabbits to the slaughterhouse and the application of an integrated quality system. Thus, farmers are not eager to use the group-housing system with natural mating due to these marketing problems.

Under field conditions, these experiments confirm that performances are lower in group-housing with AI compared to cage housing due to a lower kindling rate and a lower kit weight at weaning. Similar results were obtained in our experiment under laboratory conditions [12].

In rabbits, ovulation is a neuroendocrine reflex, typically triggered by mating or induced by exogenous GnRH administration. In this species, therefore, functional CL should not be present in the ovary of unmated animals or in the post partum period. Surprisingly, however, early studies [10] showed that up to $21 \%$ of rabbits had abnormally high plasma progesterone concentrations $(\mathrm{P}+)$ and $\mathrm{CL}$ in the post partum at the time of artificial insemination (AI). These high levels of progesterone at the time of insemination, while they did not impede GnRH-induced ovulation, were indeed responsible for anti-reproductive effects, given that most of these $\mathrm{P}+$ does were not receptive and did not become pregnant. Similar findings were also reported by Theau-Clément et al. [14], who also observed $24 \mathrm{~h}$ after $\mathrm{AI}$, in the post partum period, the presence of two populations of corpora lutea (CL) in the ovaries of does with high progesterone concentrations. In these does, the high progesterone concentration $\left(9.4\right.$ ng. $\left.\mathrm{mL}^{-1}\right)$ was an indicator of pseudo-pregnancy and none of them were fertilised.

In the present work, $\mathrm{P}+$ does were only found in the group-housing system. A progesterone concentration higher than $2 \mathrm{mg} \cdot \mathrm{mL}^{-1}$ highly affected the kindling rate of the group-housed does. These findings give strength to the current idea that, at least for reproduction purposes of rabbits, AI in group-housing is intrinsically related to low kindling rates, probably associated with pseudo-pregnancy. It remains to be established what factor indeed triggers ovulation of does under these circumstances given that mounting behaviour as evidenced by video tapes was not correlated with the high progesterone syndrome as originally suspected.

In fact, it is generally assumed that mounting behaviour among does can 
stimulate pseudo-pregnancy, because ovulation is provoked by the mounting of the buck [15]. A pseudo-pregnancy lasts for about $18 \mathrm{~d}$ and in this period a doe has a lower fertility [16].

Therefore, more research is needed to determine the causes of pseudopregnancies in group housing to improve kindling rate.

The findings of skin injuries clearly indicate that does may display aggressive behaviour to each other. The presence of the buck did not modify aggression, because the average number of does with skin injuries was not higher when the buck was left out of the group. In a previous experiment [12], it was found that the absence of a buck in a group did not lead to social instability and more aggression among does. Aggression will occur when mixing of the does the first time, because the hierarchy in the group should be established, or after introduction of a new doe in the group. In a stable group it is expected that there is little aggression between does [17]. However, our observations showed that on average 16 to $20 \%$ of the does have skin injuries and that a sudden and unpredictable rise of aggression can occur, leading to severe skin injuries to almost all the does in a group. Severe skin injuries can be seen as a problem for welfare. The reason for such outbreaks is not clear and needs more research.

\section{CONCLUSIONS}

Based on the results of this field study, the following can be concluded:

1. In a group-housing system, similar litter size, kits born alive, kit mortality and kit weight at $14 \mathrm{~d}$ can be obtained compared to a single-housing system. When natural mating is applied in group-housing, an increased number of litters can be obtained.
2. However, since AI is preferred from a management point of view, both kindling rate and kit weight at weaning are reduced in the group-housing system compared to the regular cage system.

3. In group-housing with AI, a reduced kindling rate occurs and this is partly caused by pseudo-pregnancies. Mounting behaviour did not directly cause pseudo-pregnancy.

4. Skin injuries observed in the does of the group-housing system, revealed that aggressive behaviour takes place.

5. More research is needed to solve the problems of productive performance and the aggressive behaviour that takes place before the group-housing system can be introduced into commercial rabbit reproduction.

\section{REFERENCES}

[1] Gunn D, Morton DB. Inventory of the behaviour of New Zealand white rabbits in laboratory cages. Appl Anim Behav Sci 1995, 45: 277-292.

[2] Chu L, Garner JP, Mench JA. A behavioural comparison of New Zealand white rabbits (Oryctolagus cuniculus) housed individually or in pairs in conventional laboratory cages. Appl Anim Behav Sci 2004, 85: 121-139.

[3] Hansen LT, Berthelsen H. The effect of environmental enrichment on the behaviour of caged rabbits (Oryctolagus cuniculus). Appl Anim Behav Sci 2000, 68: 163-178.

[4] Mirabito L. Effet du logement des lapines en cages rehaussées avec plate-forme: premiers résultats. In: Proc. $8^{\mathrm{e}}$ Journ Rech Cunicole, 1999, pp. 67-70.

[5] Stauffacher M. Group housing and enrichment cages for breeding, fattening and laboratory rabbits. Animal Welfare 1992, 1: $105-125$.

[6] Vastrade FM. The social behaviour of freeranging domestic rabbits (Oryctolagus cuniculus L.) Appl Anim Behav Sci 1986, 16: 165-177.

[7] Ruis MAW. Group-housing of breeding does. In: Cost 848 European programme (in press). 
[8] Coenen E, Ruis MAW, Voedsters in groepen produceren even goed als in reguliere individuele huisvesting. NOK-Kontaktblad 2003, 6: 6-8.

[9] Coenen E, Rommers JM, Francois F. De ideale rustplekaar kiest een voedster voor? NOK-Kontaktblad 2004, 2: 9, 10, 24.

[10] Boiti C, Canali C, Monaci M, Stradaioli G, Supplizi VA, Vacca C, Castellini C, Facchin E. Effect of postpartum progesterone levels on receptivity, ovarian response, embryo quality and development in rabbits. In: Proceedings of the 6th World Rabbit Congress, Toulouse, France, 1996, 2, pp 4549.

[11] Kalle G. Kaninchen in Gruppenhaltung. DGS 1994, 25: 16-20.

[12] Ruis MAW, Coenen E, Lenskens P. Kunstmatige inseminatie bij groepsgehuisvest e voedsters perspectiefvol. NOK-Kontaktblad 2003, 6: 6-8.
[13] Coenen E, Ruis MAW, Francois S. Nestkastbezoeken sterk verminderd in groupshuisvesting. NOK-Kontaktblad 2002, 4: $10-13$.

[14] Theau-Clément M, Boiti C, Mercier P, Falières J. Description of the ovarian status and fertilising ability of primiparous rabbit does at different lactation stage. In: Proceedings of the 7th World Rabbit Congress, Valencia, Spain, 2000, Vol A, pp 259-266.

[15] Hafez ESE. Rabbits. In: Reproduction and breeding techniques for laboratory animals, Ed Hafez, Lea and Febiger, Philadelphia, USA, 1970

[16] Cheeke PR, Patton NM, Lukefahr SD, McNitt JI. Rabbit production. The Interstate Printers and Publishers, Inc, Danville, Illinois, USA, 1987.

[17] Mykotowycz R, Hesterman ER. An experimental study of aggression in captive European rabbits, Oryctolagus cuniculus. Int J Behav Biol 1975, 52: 104-123. 